Lucio Fernando Oliver Cadernos Prolam/USP, v.15, n.29, p.171-191, jul/dez.2016

\title{
ALTERNATIVAS Y SALIDAS PARA LAS LUCHAS Y CRISIS HEGEMÓNICAS EN AMÉRICA LATINA
}

\section{ALTERNATIVE PATHS FOR SOCIAL STRUGGLES AND HEGEMONIC CRISES IN LATIN-}

\author{
AMERICA
}

Lucio Fernando Oliver ${ }^{1}$

Facultad de Ciencias Políticas y Sociales de la UNAM, Ciudad de México, México

\begin{abstract}
Resumen: Este escrito debate las alternativas de las luchas sociales en la crisis de las políticas de hegemonía en América Latina, con referencia a la experiencia brasileña. El vuelco a la derecha en la sociedad civil, tal como se presenta en la opinión pública y en las movilizaciones sociales permitió el retorno al autoritarismo de Estado y a las políticas de neoliberalismo salvaje. Ello plantea diversos problemas teóricos y políticos. La situación lleva a redefinir la política como una disputa por reformas profundas que enfrenten la crisis orgánica del capitalismo y del Estado en América Latina.
\end{abstract}

Palavras-chave: Brasil; América Latina; crisis política y sociedad civil.

\begin{abstract}
This paper seeks to consider theoretically the problem of alternative paths to the current crisis of left policies in Latin America, with special reference to the Brazilian experience. Its starting point is the ideological shift to the right in civil society, that is, in public opinion and social mobilizations, that rolled back to state authoritarianism and policies of savage neoliberalism. All this poses various theoretical and political problems in order to create the conditions to policies for real reforms that would allow Latin American societies to intervene actively in the confrontation of the organic crisis of capitalism and State.
\end{abstract}

Key words: Brazil; Latin America; political crisis and civil society.

${ }^{1}$ Doutor, Professor no Centro de Estudios Latinoamericanos, Facultad de Ciencias Políticas y Sociales de la UNAM, Ciudad Universitaria, Ciudad de México, México. E-mail: oliverbar@ hotmail.com. 


\section{LA PROBLEMÁTICA DE LA SUBALTERNIDAD DE LAS MASAS}

En las sociedades periféricas y dependientes como las nuestras, se reproduce día a día el dominio mercantil dinerario y político del capital (ahora globalizado) pero también se genera cotidianamente (espontáneamente) la resistencia y lucha por alternativas y salidas a la situación de opresión y explotación de las mayorías que hace parte de las grandes complicaciones estructurales. La historia moderna ha demostrado que para que esas luchas adquieran dimensión histórico política es necesario ir más allá de la protesta: que los movimientos y las fuerzas políticas de resistencia asuman que la situación de subordinación de las mayorías y la persistencia de problemas estructurales sin salidas, se basa en la subalternidad de las masas, esto es, la noción de que es imprescindible que en la sociedad prevalezcan políticas para disputar ideológica, ética y culturalmente el Estado y la dirección

ética, política, cultural, intelectual, territorial y económica de la sociedad. Este fenómeno está vinculada a la construcción de una política de "hegemonía" (en el sentido de dirección cultural e ideológica) vinculada a la lucha por la emancipación y por lo tanto distinta a la tentativa de acceder al poder del Estado tal cual existe, fenómeno de lucha que debiera definir la identidad propia de las izquierdas y hace parte del interés histórico político ideológico de las izquierdas.

Coincido con la apreciación de Giovanni Semeraro en el sentido de que la política progresista y de gran parte de la izquierda en América Latina (y en Brasil en particular) se ha ubicado hasta ahora en la demanda por derechos dentro del Estado actual y en el marco de la ideología dominante. Pero se dejó de lado la necesidad e importancia de elaborar una política de hegemonía alternativa (SEMERARO, 2007):

A hegemonia que deve ser construída pelas classes populares - alertava Gramsci "não é o instrumento de governo de grupos dominantes que procuram o consenso e impõem a hegemonia sobre as classes subalternas". Essas, ao contrário, "têm interesse em conhecer todas as verdades, inclusive as desagradáveis" (Gramsci, 2000, C 10, $\$ 41$, p. 1320) e buscam estabelecer uma "relação pedagógica" (Gramsci, 2000, C 11§ 67, p. 1505; C 13, § 36, p. 1635) entre os governantes e os governados, de tal modo que se possa superar a concepção de poder como dominação e possam ser dadas as condições para que todos venham a "tornar-se dirigentes". Não se tratava, portanto, de uma estratégia para tornar o poder vertical mais aceitável e humanizado, mas de novas relações sociais, de um novo modo de entender a política, de um novo modo de organizar a produção, cujos objetivos eram a democratização efetiva da sociedade, ou seja, a elevação intelectual e moral das 
massas, a passagem dessas da posição de dirigidos à condição de dirigentes $(\mathrm{Q} 8, \S$ 191, p. 1056) (SEMERARO, 2007, 102 y 102).

De lo anterior se desprende la necesidad de clarificar lo que supone un actuar como izquierda en las luchas políticas y sociales en América Latina.Después de la bancarrota de los países socialistas históricos (estatistas-burocráticos) y ante el desplazamiento del pensamiento crítico profundo en los últimos 17 años, estamos ante la necesidad de hacer una revisión de los planteamientos teóricos y la actuación histórica de las luchas de la sociedad civil, los movimientos sociales, los gobiernos progresistas y los movimientos políticos de las izquierdas en América Latina en las décadas recientes, revisión que abarca considerar tanto las experiencias de toda la época de dominio del capital monopólico mundial (capitalismo neoliberal, socialismo estatista) como las habidas más recientemente en el período del paso a la mundialización y transnacionalización del capital y la generalización del trabajo no especializado (17 años de propuestas de gobiernos del progresismo) (FONTES, 2010)

Por izquierda se pueden entender muchas cosas y tener de ella apreciaciones múltiples. Una apreciación crítica y concreta de la izquierda lleva a entenderla como la corriente ideológico política de la sociedad interesada en la crítica del capitalismo, de la enajenación, la injusticia y las inconsecuencias democráticas modernas y a conformar una corriente de la praxis que lucha por transformar la sociedad con organización autónoma permeada de nuevas concepciones, ideas y valores comunitarios e individuales. Para ello la izquierda requiere de la crítica histórica y social aplicada a la comprensión de los procesos y las situaciones concretas, que busca hacer avanzar a la sociedad en su conjunto, propiciando la acción política, social, cultural y económica autónoma, social y política, transformadora, de las grandes mayorías populares, tanto de la fuerza de la masa como de los individuos libremente asociados.

En términos de hegemonía alternativa, la izquierda es un movimiento que busca incidir para que la sociedad misma, como sociedad civil y como mayorías populares aprecien, distingan y enfrenten los problemas que la atraviesan como fenómenos estructurales, mismos que son resultado de las contradicciones que existen en su seno. Implica que en medio de los conflictos coyunturales cotidianos actué en la política, en la cultura, en la sociedad y en la economía para ser parte de la sociedad en movimiento que busca una salida que abra un cauce favorable a las grandes mayorías populares en términos estratégicos y políticos y en los 
distintos ámbitos de la vida social, institucional y social, es decir es una corriente ideológico política que actúa tanto desde abajo (con la acción espontánea de la sociedad civil) como desde la transformación de la propia sociedad en resistencia en una sociedad capaz de hacer política desde arriba (desde la labor consciente de la lucha por un nuevo bloque histórico).

La izquierda está obligada en tanto pensamiento social crítico y actor político, en asociación con el resto de actores políticos populares y como parte de un movimiento amplio de la sociedad civil, a diseñar e impulsar estrategias y políticas a corto, mediano y largo plazo para enfrentar y superar los problemas estructurales que agobian a las sociedades modernas, tanto centrales como periféricas.

Consideramos que existen dos elementos centrales de las sociedades contemporáneas, producto del desarrollo capitalista a nivel global, que condicionan hoy la lucha de las izquierdas:

a) La sociedad civil actual está conformada por grandes mayorías que viven de su trabajo, está constituida por una gran masa precarizada de explotados globales, compuesta por un nuevo y distintivo tipo de trabajadores: los que a cambio de un salario realizan el trabajo abstracto de múltiples maneras cada vez más informales, que laboran en industrias, comercio y servicios globales con características de maquiladoras, junto con los trabajadores que son analistas simbólicos de la administración de la circulación y la producción, los servicios y el comercio, todos ellos vinculados con la producción de riqueza social dirigida por las grandes corporaciones mundiales, los grandes conglomerados capitalistas del agro, el comercio, los servicios y la industria urbana. Constituyen los explotados globales del capitalismo contemporáneo(CASANOVA, 2009)

b) La izquierda se ubica en la resistencia y lucha de los explotados globales y asume su papel de reconocer su unidad y diversidad, de buscar, como parte de esa misma lucha, el nivel político programático común que ayuda a unificar, elevar la organización y la conciencia de los movimientos sociales y la sociedad civil. Es decir, la izquierda actúa en la sociedad civil para construir una nueva ecuación del Estado integral o para incidir en la relación de Estado y sociedad civil, a partir de reconocer y actuar en la unidad orgánica de la sociedad política y la sociedad civil. Articular la lucha social y la lucha política e ideológica del conjunto de explotados globales de cada país en la búsqueda de reformar el Estado, entendido en un sentido amplio: lograr la hegemonía civil y la hegemonía política, bajo 
control social y, basado en la dinámica económica, política e ideológica de las trincheras populares.

\section{LA EXPERIENCIA DE LOS GOBIERNOS PROGRESISTAS. LUCHAS Y CRISIS HEGEMÓNICAS EN AMÉRICA LATINA DEL SIGLO XXI}

Partimos de valorar la importante experiencia de lucha de los trabajadores en la historia reciente de América Latina. Pensar las luchas y crisis hegemónicas en la actualidad nos conduce a una valoración de las estrategias y políticas de los movimientos sociales y políticos progresistas y de izquierda en la vida estatal latinoamericana. En primer lugar, podemos iniciar considerando las experiencias bajo el primer ciclo neoliberal salvaje de la globalización de fines del siglo XX, que va de 1982 a 1999.

Se trató de un ciclo dominado por la articulación de las clases capitalistas monopólicas nativas con las clases capitalistas mundiales a partir de un proceso de aceleramiento de la transnacionalización del capital, de la entronización de clases políticas subordinadas a los Estados de competencia y de predominio de la ideología neoliberal.

En los últimos veinte años del siglo XX se produjo en toda América Latina una profunda transformación del capitalismo y del Estado. Las economías se reestructuraron hasta convertirse en formas productivas transnacionalizadas y financierizadas con base en las privatizaciones de las empresas y bienes públicos, la desindustrialización nacional, la dominancia de las bolsas de valores y las instituciones financieras, las contrarreformas de los Estados y la instauración de los Estados burocráticos de valorización de competencia mundial. Las ideologías nacional desarrollistas fueron sustituidas por ideologías transnacionales de mercado, de individualismo y pensamiento único.

Como resultado de ese ciclo neoliberal se produjo el decrecimiento de las economías nacionales, la dependencia redoblada, la fragmentación, precarización y recomposición informal de las sociedad civiles, y en todos los países de América Latina se gestó la crisis orgánica del Estado, expresada en una no correspondencia entre Estados y sociedades (OLIVER, 2016).

Lo anterior llevó a una explosión de inconformidades de los trabajadores agrícolas y campesinos, de las masas de trabajadores urbanos y de gran parte de los sectores medios, lo 
que se tradujo en el surgimiento de movimientos sociales de resistencia y lucha (el caracazo en Venezuela, el movimiento del EZLN en México, el MST en Brasil, etc.), situación que abrió las dos grandes vertientes resolutivas del siglo XXI: a) los gobiernos de emergencia neoliberales: autoritarios, con de Estados de excepción y alineados a una seguridad hemisférica (Plan Colombia y Plan Mérida); y en sentido opuesto, b) los variados gobiernos progresistas de Sudamérica y en Centroamérica:

[...]los gobiernos del Ciclo de Impugnación neoliberal en América Latina, CINAL surgen como producto y respuesta a la activación de las luchas populares desplegadas en los años previos a su llegada a la conducción estatal. Esto significa que se originan en esa activación, pero sus respuestas concretas también son el resultado de las relaciones de fuerzas específicas que les dan origen y que se redefinen a partir de un punto determinado de inflexión. (THWAITES; OUVIÑA, 2016, p. 21).

¿Cómo caracterizar a esos gobiernos que al impugnar el ciclo neoliberal se asumen como progresistas?

Han prevalecido dos maneras de caracterizarlos. La primera es considerar que se tienen que medir a partir de reconocer su condición reformista y no revolucionaria. Es decir valorarlos como una opción de transformación lenta y parcial del modo de producción capitalista, bajo las condiciones generales de dominio mundial del capital en un contexto de relaciones de fuerzas "bajo empate” entre las oligarquías transnacionales y los trabajadores explotados globales. La estimación de su praxis se produce en el sentido de si estos gobiernos logran, con una política de conciliación de clases y pacificación social, intervenir cambiando el Estado para introducir estructuralmente una regulación política y social de la reproducción social y la acumulación, haciendo avanzar políticas económicas de conducción estatal que producen una apropiación de la plusvalía para proyectos estructurantes de la vida social, valorar su capacidad para interpelar al capital financiero poniendo límites a su apropiación privada de riquezas sociales, y modificar las políticas sociales y públicas. La segunda manera es evaluar su capacidad para impulsar una política de hegemonía alternativa, esto es qué tanto abren paso a un proceso de transición antineoliberal y anticapitalista, logrando una nueva conducción político ideológica en la sociedad, en el contexto de la crisis mencionada de hegemonía del capitalismo neoliberal. 
Desde cualesquiera de las dos perspectivas analíticas hoy podemos constatar que con los gobiernos progresistas, sin considerar sus diferencias menores entre ellos, continuó vigente el modo histórico de acumulación capitalista en su variante neoliberal, que enfatiza el predominio privado, el dominio financiero y la sobreexplotación del trabajo y la explotación de recursos naturales:

[...] sostenemos que aún está vigente el modo de acumulación prevaleciente en el capitalismo global, de carácter neoliberal, desplegado como reacción restauradora al formato interventor benefactor...Las diferencias de las políticas encaradas por los gobiernos de la región se relacionan con el grado de profundidad de la crisis que les dio origen en cada caso y con la viabilidad política de los proyectos que intentaron salidas autonomizadas del neoliberalismo y de sus beneficiarios más prototípicos. Sin embargo, tales políticas no transcendieron la etapa de acumulación neoliberal, entre cuyas características centrales están el predominio de la financiarización globalizada y la intensificación de la explotación de bienes naturales (extractivismo) (THWAITES; OUVIÑA, 2016. p. 19)

Sin embargo para la crítica de izquierda es fundamental valorar la experiencia de los gobiernos progresistas bajo la segunda perspectiva: su estrategia y sus políticas en el sentido de que tanto incidieron en transformar las formas ideológicas de la sociedad, “[...] las formas jurídicas, políticas, religiosas, artísticas o filosóficas, en una palabra las formas ideológicas en que los hombres adquieren conciencia de este conflicto y luchan por resolverlo [...]."(MARX, 2001).

Es imprescindible valorar hoy, después de un ciclo de gobiernos progresistas, considerar si dieron lugar y auspiciaron una "disputa hegemónica" con respecto a las clases dominantes. Al respecto hay diversas apreciaciones. El grupo de Estado con el que trabajo en CLACSO sostiene, por ejemplo, que:

[...] lo que hubo fue "un escenario de disputa hegemónica en la región, que es lo que caracteriza al Ciclo de Impugnación al neoliberalismo en América Latina (CINAL), con la emergencia de gobiernos cuestionadores, en el discurso y en ciertas prácticas, de las lógicas dominantes a nivel global, y que en la mayoría de los casos estuvieron precedidos de fuertes movilizaciones populares desde abajo, signadas por una misma tónica de impugnación del ideario neoliberal (THWAITES; OUVIÑA, 2016. p. 20) 
Llegamos así a la interrogante de fondo: si hubo una disputa hegemónica en la experiencia de estos gobiernos. Sin pretender proponer una apreciación tajante y definitiva, sino embargo considero que no hubo tal disputa sino algunas aproximaciones, menores, embrionarias, a ella. No se desarrollaron políticas de incidencia profunda en la ideología que es el ámbito en que la sociedad toma consciencia de las contradicciones y lucha por resolverlas. Incluso el fenómeno del cesarismo que fue un aspecto dominante de los procesos políticosociales bajo esos gobiernos muestra que la política se concentró no en la lucha y desarrollo ideológico de la sociedad sino en torno del apoyo a líderes carismáticos.

Bajo la experiencia de los gobiernos progresistas no se procesó una lucha social por un bloque histórico nuevo, que diera lugar a la "catarsis", es decir a la superación del nivel de la lucha por derechos -lo cual era absolutamente necesario- en una lucha mayor, encaminada a que la sociedad asumiera la dirección del proyecto nacional y social. Hubo ausencia de una vinculación política ideológica entre la expansión de una forma productiva social-pública (que prácticamente no existió como forma autónoma al capitalismo) y una sociedad civil y movimientos sociales que fueran participes en el debate y deliberación de los asuntos públicos, que propiciara el incremento significativo de la incidencia social y ciudadana en la definición del rumbo del país respecto a los aspectos problemáticos colectivos: salud, educación, empleo, vivienda, servicios, acumulación, fondo social, etc. Tampoco hubo un movimiento de reforma cultural y ética respecto de las relaciones sociales mercantil capitalistas que siguieron dominando la reproducción social. Así, faltaron los elementos constituyentes de una real disputa por el Estado, para cambiar el Estado. Faltó una estrategia de reformas estructurantes de otra forma del poder que permitieran un empoderamiento popular: reformas constitucionales del poder ejecutivo, judicial, poder parlamentario, del poder mediático, del poder agrario, etc.

Es necesario estudiar a fondo porqué la confrontación político partidaria no se llevó al terreno de una real disputa de proyectos político culturales que proyectara un cuestionamiento y cambio de valores colectivos, de concepciones del mundo, de nociones éticas, del sentido común, de las costumbres.

En el contexto de los gobiernos progresistas tampoco los movimientos autónomos de izquierda en la sociedad consiguieron incidir en un cuestionamiento de masas al conformismo capitalista mercantil, a la separación política-sociedad-economía, a las contradicciones 
persistentes del capitalismo periférico dependiente que generan la desigualdad social y los problemas estructurales de nuestras sociedades.

Frei Betto, dirigente popular crítico y partícipe durante unos años de la experiencia del gobierno Lula, resume bien la ausencia de una política de hegemonía de los extraordinarios gobiernos progresistas de Brasil en los últimos 13 años:

Los últimos 13 años fueron mejores para 45 millones de brasileños que, beneficiados por los programas sociales, salieron de la miseria; para quien recibe el salario mínimo, revisado anualmente por encima del nivel de la inflación; para quienes tuvieron acceso a la universidad, gracias al sistema de cuotas, al ProUni y al Fies; para el mercado interno, fortalecido por el combate a la inflación; para millones de familias beneficiadas por los programas Luz para Todos y Mi Casa, mi Vida; y para todos los pacientes atendidos por el programa Más Médicos. A pesar de todo nos equivocamos. El golpe fue posible también debido a nuestros errores. En 13 años no promovimos la alfabetización política de la población. No tratamos de organizar las bases populares. No valoramos los medios de comunicación que apoyaban al gobierno ni tuvimos iniciativas eficaces para democratizar los medios. No adoptamos una política económica orientada hacia el mercado interno.En los momentos de dificultad llamamos a los incendiarios para apagar el fuego o sea a los economistas neoliberales, que piensan con la cabeza de los pudientes. No realizamos ninguna reforma estructural, como la agraria, la fiscal y la previsional. Ahora somos víctimas de la omisión en cuanto a la reforma política.¿En qué baúl avergonzado guardamos a los autores que enseñan a analizar la realidad bajo la óptica liberadora de los oprimidos? ¿Dónde están los núcleos de base, las comunidades populares, el sentido crítico en el arte y en la fe?¿Por qué abandonamos a las periferias; tratamos a los movimientos sociales como menos importantes; y cerramos las escuelas y los centros de formación de militantes? Fuimos contaminados por la derecha. Aceptamos la adulación de sus empresarios; usufructuamos sus regalías; hicimos del poder un trampolín para el ascenso social.Cambiamos un proyecto del Brasil por un proyecto de poder. Ganar elecciones se volvió más importante que promover cambios a través de la movilización de los movimientos sociales. Engañados, acatamos una concepción burguesa del Estado, como si él no pudiera ser una herramienta en manos de las fuerzas populares y tuviera que ser siempre amparado por la élite.Llegó pues la factura de los errores cometidos. Y en las calles del país la reacción al golpe no tuvo fuerza para evitarlo.Pero dejemos el pesimismo para días mejores. Es la hora de hacer autocrítica en la práctica y de reorganizar la esperanza". (BETTO, 2016, s.p.)

\section{Podemos considerar después de este recuento analítico que ni en el Brasil progresista ni}

en los demás países del mismo carácter de América del Sur existió una política de hegemonía alternativa que se expresara en una lucha por reformas profundas con contenido y perspectivas estratégicas:

El mantenerse en el poder, así fuese al costo de pactos espurios, fue más importante que alterar las estructuras arcaicas de la sociedad brasileña. Trece años de gobierno y ninguna reforma, ni la agraria, la laboral o la tributaria. Hoy, el PT es víctima de la 
omisión de una reforma política"2 (BETTO, 2016, s.p.)

\section{EL PROBLEMA DEL ESTADO}

Estas líneas argumentativas de carácter general hacen una valoración de conjunto de la experiencia de los gobiernos progresistas de América Latina, pero con ello se desvanecen las importantes diferencias entre los distintos casos nacionales y en las políticas de los variados momentos de cada uno de esos gobiernos, pues algunos de ellos promovieron con más fuerza elementos de lucha por la hegemonía: la organización popular autónoma (Venezuela), el debate (Ecuador), la reforma intelectual y moral (Bolivia), la recuperación del Estado y la inclusión social (Brasil).

Me parece que los gobiernos progresistas de esta primera década y media fueron parte de un proceso de resistencia y recuperación de instituciones nacionales y sociales, lo cual es la base y el germen de una lucha de mayor alcance, pero como podemos reconocer después de 13 años, de por sí no constituye los elementos suficientes de una disputa por la hegemonía.

Como señala François Houtart, los gobiernos progresistas pusieron en el centro la retomada del Estado, en sentido clásico (HOUTART, 2016). Lo hicieron en sentido de volver a la regulación capitalista desde la burocracia de los Estados, con centralización técnica de gestión, con administración progresista de los recursos públicos pero sin políticas de reformas de fondo, incluso algunas veces cediendo a las presiones internacionales de ajuste. Además la conducción de la gestión del Estado apeló a formas despolitizadoras, como los liderazgos carismáticos, en lugar de plantearse nuevas nociones de participación social en los asuntos públicos y de incidencia de la sociedad en los asuntos del Estado.

En general los gobiernos progresistas fueron un respiro importante de resistencia ante la ofensiva neoliberal pues en ellos prevaleció la intención de recuperar cierta soberanía política del Estado nación, y una autonomía relativa para una gestión adecuada, una buena administración con rendición de cuentas (no en todos los casos), la promoción de justicia social y el recurso limitado y siempre focalizado en situaciones especiales y conflictivas a la represión, con el cuidado de sostener un sistema político electoral legítimo y consensual, lo

\footnotetext{
${ }^{2}$ FREI BETTO, "Começar de novo" (Comenzar de nuevo), publicado en: Correio da cidadania on line, Brasil, 6 de septiembre de 2016.
} 
que como se sabe no eliminó las prácticas de corrupción sobre todo las relacionadas con la relación entre los partidos y dirigentes y las empresas privadas y públicas.

Las políticas de cambio de los gobiernos progresistas terminaron por contribuir a lo contrario de lo que era su intención: a la reproducción del orden del capital, a privilegiar la acumulación de capital, empero abriendo espacio para nuevas políticas públicas, para políticas sociales incluyentes de alcance prácticamente universal, con regímenes políticos de conciliación y acuerdo respeto a la diversidad de posiciones de las fuerzas políticas y sociales.

La intelectualidad crítica hoy considera que la recuperación del Estado se realizó bajo políticas de conciliación de clases y pacificación social, sin proyectos de poder popular que significaran la disputa por el Estado y por una concepción del poder y de las decisiones públicas (BRAGA, 2016; OLIVER, 2016). En general no se promovieron proyectos político culturales alternativos que hubiesen implicado la organización autónoma de la sociedad, confrontación por reformas estructurales, debates nacionales de carácter social y político ideológicos respecto a los problemas de la sociedad y lo público, encaminados a nuevos proyectos nacionales, promotores de otras formas productivas, otra relación entre sociedad, economía y Estado, ninguna reforma intelectual y moral que hubiese tenido como objetivo real una modificación de las relaciones de fuerzas.

En la relación Estado-economía los gobiernos progresistas se dejaron atrapar por las ventajas inmediatas del rentismo y el extractivismo, descuidando la creación de nuevas formas productivas de economía social y estatal nacional:

Lejos de perseguir las estrategias de transformación de la matriz productiva enunciadas como deseables, primó el aprovechamiento inmediato de los recursos provenientes de la estructura establecida. Se concentraron en capturar y gestionar una masa de capital que, tanto por la forma en que se valoriza como por los actores que la encarnan, funciona en el marco de la lógica de la mercancía y la ganancia, en general, y del ciclo neoliberal, en términos específicos de la etapa del capitalismo mundial. Por eso se advierte que durante la coyuntura de bonanza de precios no se apuntó de modo consistente a revertir la estructura productiva para dotarla de mayor diversidad y autonomía, sino que las políticas de continuidad adoptadas no modificaron o, incluso, contribuyeron a acentuar los rasgos de reprimarización y extractivismo preexistentes (THWAITES, OVIÑA, 2016, p. 17).

Un aspecto positivo de las políticas de recuperación delos Estados, sin embargo, fue que éstos se constituyeron en mecanismos de resistencia al dominio salvaje del capital y en 
mecanismo de satisfacción de aspectos de la demanda popular frente a los fenómenos más negativos del neoliberalismo que prevalece hoy a nivel mundial.

[...] la experiencia latinoamericana reciente muestra que, bajo ciertas circunstancias se torna factible que desde el propio Estado se desplieguen mecanismos de resistencia a los aspectos más perversos del capital para la vida de los pueblos, poniéndose de manifiesto la dimensión contradictoria del Estado. En concreto, cuando las relaciones de fuerzas permiten que en los Estados se articulen procesos políticos y sociales, nacionales y regionales, impulsados por movimientos populares, se abre la posibilidad de empujar políticas favorables a ciertas demandas e intereses de las clases y grupos subalternos. A su vez, la profundidad de las transformaciones, así como el alcance y significado de las mismas, se entronca con los marcos que impone la estructura de dominación capitalista a escala global, y con la maduración de las condiciones subjetivas que hacen o no posible producir cambios sustantivos (THWAITES, OVIÑA, 2016, p. 12-13).

La imposibilidad de ir más allá de la recuperación reguladora del Estado abarcó no sólo a los gobiernos, sino al conjunto de las fuerzas políticas progresistas y de izquierda, a los sectores avanzados de la sociedad civil y de los movimientos sociales, por ello no se logró procesar el paso de la resistencia al capital hacia la lucha por la hegemonía y se dio poca importancia a lograr un nivel alto de organización y capacidad crítica que diera lugar a un movimiento autónomo y un proceso de lucha consciente que generara una real disputa de proyectos nacionales y sociales.

La ausencia de una política de hegemonía alternativa no resta fuerza al hecho de que bajo los gobiernos progresistas avanzó la creencia popular en las fuerzas propias de los países de América Latina y las potencialidades de su integración democrática. Y no obstante lo limitado en tiempo de las políticas de acercamiento e integración de proyectos e instituciones, se estimuló la cultura y la identidad de una región que se caracteriza por su amplia diversidad. Países de indios, caboclos, negros, indígenas y pobres, comunitarios, mujeres, jóvenes. Eso hoy es motivo de preocupación de las derechas que están intentando eliminar.

Un elemento controversial por sus resultados contradictorios fue el éxito de las políticas económicas de crecimiento y de ampliación del consumo de masas, en los ramos de seguridad alimentaria, combate al hambre e inclusión por medio de fondos y paquetes en dinero de grandes sectores empobrecidos de población. Al no estar esas políticas vinculadas a una disputa por la hegemonía, ese logro se constituyó en una ciudadanía económica limitada y asociada a la economía mercantil y al lucro sin que tuviese un correlato con el despliegue de una nueva ciudadanía política: 
La expansión de bienes de consumo masivo a escala global y su exposición publicitaria como objetos aspiracionales de alcance universal, interpela directamente a grandes porciones de las clases populares del planeta, logrando que operen como una suerte de "cemento" ideológico y cultural del orden capitalista. Nos referimos al amplio campo de la electrónica (celulares, computadoras, televisores, equipos de música, electrodomésticos), los automóviles y la indumentaria (calzado deportivo, ropa, cosméticos), que se constituyen en una suerte de "artefactos" de deseo globalizados, que se imponen a través de los medios masivos de comunicación y las redes sociales, y donde aunque pueda resultar paradójico el mejoramiento tecnológico no alarga su ciclo de vida "útil" sino que, por el contrario, lo disminuye. Tales objetos icónicos, además de exacerbar el fetichismo mercantil, operan como homogeneizadores de las aspiraciones masivas y, a la vez, como patrones diferenciadores en función de las posibilidades de acceso a su goce. Si tal como ha planteado Tomás Moulián (1998), consumir es una actividad cotidiana e imprescindible ligada a la reproducción material, pero también espiritual (cognitiva, sensorial y emocional), la hipertrofia del consumo a través de múltiples dispositivos asentados en cadenas crediticias, de endeudamiento, subsidios y flujos dinerarios, nos obliga a repensar de manera más compleja el arraigo de la hegemonía burguesa -e incluso la persistencia de un "neoliberalismo desde abajo"- en las propias subjetividades de las clases subalternas, en la medida en que "el consumo es una mediación y un incentivo que, junto al dispositivo de la deuda, impulsa a nuevas modalidades de creación de valor", a partir de la penetración del sistema financiero en la economía de los propios sectores populares(GAGO, 2014,p. 218)”.

\section{EL VUELCO A LA DERECHA EN LA SOCIEDAD Y EN EL ESTADO POLÍTICO. LA SITUACIÓN ACTUAL DE AMÉRICA LATINA}

En el actual contexto de vuelco a la derecha en América Latina cabe interrogarse por el horizonte actual de las luchas sociales populares, por los elementos con que cuenta la izquierda para encabezar una nueva disputa de proyectos, en el marco de un retorno al autoritarismo neoliberal y al Estado del orden del capital en un contexto de crisis política y económica del orden mundial.

Primeramente habrá que dejar claro que los actuales gobiernos de la derecha de América Latina se apoyan en la vigencia hegemónica de la globalización y el neoliberalismo a nivel mundial, con repercusiones en nuestra región ubicada en la órbita del dominio imperial estadounidense (con una mayor interferencia directa del gobierno actual de ese país con posiciones y visiones de ultraderecha). A nivel interno en los países de América del Sur las fuerzas económicas, ideológico políticas del neoliberalismo local canalizan sus políticas por la vía de la restitución de un proyecto que fue cuestionado por las luchas sociales en el pasado reciente: el de los Estados nacionales de competencia que dan la espalda a las necesidades mayoritarias de la sociedad y a los problemas estructurales y aquellos surgidos por la 
desigualdad y la exclusión. Por ello es posible que se agudicen las protestas y las crisis políticas en América del Sur dadas la falta de legitimación y representatividad de las nuevas clases dominantes y dirigentes que buscan imponer una contrarreforma para beneficiar a la acumulación de capital y destruir los logros sociales y políticos de los gobiernos otrora progresistas.

La derecha latinoamericana que ha recuperado la dirección de algunos gobiernos, tanto por medio de elecciones legítimas como a través de golpes parlamentarios de Estado, desarrolla sus políticas en una situación internacional que tiene los siguientes rasgos:

a) El poder de la globalización en curso como revolución pasiva mundial. No obstante la crisis de los Estados neoliberales y la pérdida de legitimidad de las clases políticas de ese carácter, sigue en pie el dominio mundial de las fuerzas transnacionales que hacen parte de la globalización capitalista. Su fuerza está basada en la articulación corporativa transnacional de un posfordismo con un fordismo periférico. Hay una revolución técnica y científica en los procesos productivos, el comercio y los servicios que, con elementos comunicacionales y cibernéticos, transforma la economía y la sociedad en su conjunto. Ello crea la base material e intelectual de una revolución pasiva que incluye una explotación global del trabajo asalariado aunada al trabajo de los analistas simbólicos, pero lo hace ignorando las demandas y la participación de los trabajadores. Además, y como parte de los mecanismos de la expansión global del nuevo capitalismo transnacional persiste el dominio del capital financiero en los Estados neoliberales latinoamericanos.

b) La agudización de las guerras de intervención por el control geopolítico de las grandes potencias. A pesar de las transformaciones que la globalización ha impuesto en la producción y la circulación mundiales, sigue vigente la histórica división internacional entre Estados Potencia y Estados periféricos. Y el orden mundial está en crisis por la existencia de diversas potencias en conflicto: Estados Unidos y Alemania en Occidente, China y Rusia en Oriente, lo que reproduce y acentúa las disputas político militares. EUA ha sofisticado su diseño geopolítico de dominio y redoblado su ingerencismo pragmático en América Latina.

c) El posmodernismo fincado en la violencia. En el ámbito cultural ideológico la fase de la globalización se expresa en el posmodernismo de Estado, que conlleva la creación política del culto al mercado, al individualismo capitalista y a la iniciativa empresarial, que 
son la contrapartida de la normalización de la desigualdad y la violencia con las políticas militarizadas de seguridad pública y seguridad interna.

En las sociedades latinoamericanas el vuelco a la derecha muestra que:

d) Lo viejo aún sigue vivo. En la crisis lo viejo no acaba de morir y lo nuevo no se logra afirmarse. Como elementos constituyentes de lo viejo cabe señalar que la actual corriente de derechas busca también el regreso a la imposición neoliberal. Los intelectuales y medios de comunicación de esa corriente luchan cotidianamente por irradiar un neoliberalismo interno en las instituciones, en las escuelas, en los medios de comunicación, en los espacios sociales; por moldear una vida basada en el individuo líquido exitoso e hipermoderno. Pero todo ello se enfrenta a la realidad del avance de la precarización social del capitalismo transnacional, a la debilidad interna e internacional que produce la desnacionalización y debilitamiento social, al empobrecimiento nacional y social producido por la privatización y la mercantilización de empresas públicas y de bienes comunes, así como a la enajenación aguda del ser humano que forma la concepción privatista y egoísta de la vida. Esas políticas engendran continuamente la crisis política en las sociedades latinoamericanas.

e) Lo viejo también se expresa en la tendencia a construir un "Estado autoritario neoliberal del Orden" que se corresponde al denominado "fascismo societal". Ello promueve comportamientos agresivos de la sociedad del "orden", que continuamente quitan la máscara de liberalismo democrático para mostrar la cara de un poder impositivo autoritario. Ello ocurre por medio de la manipulación mediática el sometimiento del sistema judicial y del sistema de partidos que representan los vicios asociados al Estado patrimonialista de la oligarquía política autoritaria tradicional.

f) Por ello en el ámbito institucional se está gestando un Estado de excepción permanente para sostener con la violencia y el autoritarismo las formas democrático liberales en crisis de legitimidad. Las políticas de desigualdad, de precarización extrema de la gran masa de trabajadores, la negativa a ofrecer recursos para atender las necesidades sociales urgentes, las condiciones sociales creadas por la privatización de los bienes públicos, la disminución de derechos sociales, el mayor peso de entidades no institucionales con poder propio como el crimen organizado y las economía ilegales, la violencia social, la servidumbre a las corporaciones y los bancos, genera constantes crisis que abren la puerta a un Estado de excepción y de control social y político. En casos extremos, impulsan la militarización 
acentuada de la seguridad pública en toda la sociedad.Habrá muchas dificultades para que el proyecto de derecha se estabilice pues hay una especie de hegemonía liberal rota que genera constantemente crisis políticas y crisis de representación, que acentúa constantemente la tentación del recurso al autoritarismo de Estado. Ello en un contexto de decrecimiento y recesión en Occidente que afecta directamente a los países de la región de América Latina.

g) La lucha de las derechas contra la corrupción está encaminada a criminalizar a los movimientos sociales y grupos políticos progresistas y a ocultar las formas tradicionales oligárquicas de acumulación de capital. Se cobija publicitariamente y mediáticamente en la lucha contra la corrupción general, pero rápidamente asoman los elementos del programa neoliberal oligárquico empresarial. Con las movilizaciones de la derecha en la sociedad civil se ha abierto paso, en complicidad con los políticos de la derecha y ultraderecha y a través de los grandes medios de comunicación, una particularidad: la propalación en las clases medias y en una parte de los sectores populares, de sentimientos políticos de odio social, clasista, racista, juvenil, femenil, regional, religioso, homofóbico y antiindígena. El aventurerismo de las derechas es evidencia de la impotencia epocal de esa corriente para desplegar una política de hegemonía propia que le permita dominar con estabilidad.

\section{EL TEJIDO SOCIAL DE LA DIVERSIDAD Y LA CRISIS ACTUAL}

La situación actual evidencia que la izquierda que pretende salidas para las luchas y crisis hegemónicas en América Latina tiene la posibilidad de una política de hegemonía alternativa que resulte de repensar sus concepciones, sus proyectos, su programa de lucha, sus lineamientos políticos en la situación de dominio mundial neoliberal y su vínculo con las luchas sociales de la diversidad.

Al igual que en otras latitudes del mundo, en América Latina los explotados precarizados globales son portadores de experiencias e iniciativas políticas y culturales de diferente tipo, de experiencias de afirmación cultural, política e identitaria que conforman el nuevo abanico de la diversidad societal, política y cultural popular latinoamericana.Esa masa vive en condiciones de sobreexplotación, despojo de recursos naturales, atentado contra las formas comunitarias y colectivas de vida, falta de ingresos suficientes y satisfactores necesarios como educación, salud, vivienda, seguridad y empleo. No obstante, es el sustento 
de un nuevo tejido social, sociopolítico y sociocultural de nuestras sociedades latinoamericanas.

Los explotados globales han conformado una sociedad civil con nuevas características: son la confluencia de una gran cantidad de formas de agrupamiento y organización que terminan siendo eje de movimientos sociales: étnicos, etarios, de barrio, de género, de lucha cultural de favelados y marginados, de colectivos pertenecientes a barrios urbanos, de comunitarismo, de lucha por una nueva reforma agraria, por el derecho a la ciudad, contra la impunidad y por una justicia real, por una ciudadanía deliberativa en asuntos de reforma urbana, etc. Se trata de una diversidad de luchas que han desarrollado experiencias colectivas, arraigo local, identidades sociales activas y una visión crítica de sociedad y de la cultura a lo largo de los últimos treinta y cinco o cuarenta años y constituyen una gran riqueza sociopolítica y cultural de la sociedad. Los gobiernos progresistas no lograron valoraron suficientemente ese caudal de movimientos y su acumulación de experiencias, intereses, demandas.

En general esos diversos movimientos que constituyen el tejido real de los sectores populares de la sociedad civil han desarrollado luchas caracterizadas por su particularismo y localismo, sin que los esfuerzos políticos por agruparlos hayan logrado una perspectiva unificada de conjunto y una apreciación política común que genere un proyecto de emancipación articulado que entronque con una perspectiva de autonomía integral y transformación del Estado, capaz de lograr un nuevo contenido de los derechos y libertades. Se trata, sin embargo, del proceso catártico que al generar una perspectiva y un proyecto de izquierda unificada tiene los elementos para ser el punto de partida para una nueva política de hegemonía basada en un espíritu de escisión.

[...] delimitar el nivel específico de relación de fuerzas en pugna en cada sociedad, resultaba fundamental en la construcción de un proyecto emancipatorio de largo aliento que lograse quebrantar la condición subalterna de las clases populares. Su avance y/o retroceso puede medirse en función de lo que Gramsci caracterizaba como el "grado de homogeneidad, autoconciencia y organización alcanzado por los diversos grupos sociales" (Gramsci, 1999: 36), yendo desde ese nivel primigenio de rebelión "elemental", inmanente a toda relación hegemónica, que aún no contempla la necesidad de aunar sus demandas con los de un sector más vasto, y pasando por la asunción de una solidaridad de intereses entre todos los miembros de un mismo grupo social, hasta la fase intersubjetiva en que se tiende a superar cualquier resabio de corporativismo, incorporando como propios los intereses de otros grupos subordinados, y difundiéndolos por toda el área social. Como veremos, este momento, que Gramsci definía como catártico, es el que permite pasar de una fase 
“económico-corporativa", a una "ético-política (THWAITES; OUVIÑA, 2016, p. 14$15)$.

Una política de hegemonía conlleva superar la fragmentación de las luchas sociales. Para ello las figuras intermedias que tienen el papel de organizadores y mandos en la sociedad y en el Estado pueden abogar por la unificación y la centralidad concertada entre los movimientos de la diversidad, de tal forma de promover la elevación del tejido social amplio hacia un movimiento político nacional, orgánico. La política de izquierda está referida a hacer consciente una inconformidad espontánea y conformar la lucha política como lucha orgánica de la diversidad.

Al respecto, Mabel Thwaites y Hernán Ouviña nos advierten de las dificultades para procesar la unidad, centralidad y elevación política conjunta de la diversidad.

[...] las que están en juego en los actuales procesos latinoamericanos de impronta popular son lógicas diversas, no siempre fáciles de armonizar. Las lógicas nacionalpopular y socialista ponen el eje en la soberanía nacional, la democratización y la distribución de la riqueza, lo que implica el fortalecimiento del Estado para implementar políticas públicas favorables a los sectores populares. La lógica de la decolonización, en cambio, pone el acento en "la plurinacionalidad, los derechos a las diferencias, la soberanía de los pueblos indígenas en sus territorios, la autonomía de pueblos, comunidades y movimientos, el pluralismo jurídico, el rechazo al desarrollismo/extractivismo y el reconocimiento de los derechos de la Madre Tierra" (Lander, 2011: 127). Articular ambas lógicas es una empresa compleja, ya que arraigan en historias, tradiciones, imaginarios y sujetos socio-políticos diversos. Para lograr su convergencia en senderos comunes hace falta pasar por arduas negociaciones e intercambios que impliquen aprendizajes recíprocos y autocuestionamientos reflexivos (THWAITES; OUVIÑA, 2016, p. 27).

La cuestión de una política de hegemonía no está articulada a solo generar una nueva cultura nueva, sino a procesar una nueva identidad de la diversidad colectivamente construida (TAPIA, 2006) Ello implica partir del encuentro y la confrontación de valores y de praxis:

La cosmovisión decolonial, ambientalista y anti-productivista puede ser un referente moral incontrastable, pero la cuestión pasa por elucidar si resulta capaz de acumular la fuerza necesaria como para encarnar en un proyecto político de masas con potencialidad anti-sistémica, sin lo cual cualquier cambio es impensable. Y no es lo mismo batallar contra el consumismo en sociedades opulentas que en aquellas deprivadas de los bienes más elementales para la subsistencia digna o en las que la desigualdad y las injusticias sociales son flagrantes(THWAITES; OUVIÑA, 2016, p. 28).

\section{LA LUCHA DE POSICIONES}


Está en primer término, para la izquierda, como un problema de una política de hegemonía, la forma y los tiempos electorales y parlamentarios.

[...] los Estados viraron hacia un mayor margen de acción, tanto con respecto a los determinantes de la economía mundial y sus expresiones institucionales de poder, como en relación a los poderes dominantes al interior del espacio territorial nacional. Sin embargo, la apuesta al permanente refrendamiento electoral a través de los formatos clásicos de representación liberal tuvo el paradojal efecto de otorgar una fuerte legitimidad a los gobernantes, pero también de orientar las acciones hacia medidas de corto plazo y para obtener resultados inmediatos. Los tiempos electorales no suelen ser compatibles contransformaciones que requieren largos procesos de maduración y disputa hegemónica, por lo que la capacidad de maniobra para impulsar cambios profundos también se encuentra acotada (THWAITES; OUVIÑA, 2016, p. 15).

Para alimentar una política de hegemonía la izquierda tiene ante sí la lucha por nuevas concepciones y prácticas políticas en la propia sociedad civil. El problema fundamental es la lucha por la hegemonía civil y la dimensión ideológico-cultural de la sociedad civil. En ese sentido hay ya un acumulado de nuevas maneras de concebir la política en el Estado moderno. Enumeremos algunos planteamientos que han aparecido en las luchas sociales de este siglo: la sociedad como fuente deliberativa y decisoria de lo público. Las formas políticas tienen nexos orgánicos con la sociedad civil por lo mismo los programas y las acciones expresan lo acumulado de los movimientos sociales y las experiencias populares de organización política social. Al respecto se puede considerar que lo importante es ir configurando escenarios alternativos en la vida de la sociedad civil:

[...] la cuestión de la transición hacia formatos consistentemente alternativos al neoliberalismo y, aún más, hacia el post-capitalismo no se puede definir y juzgar por las medidas que sostienen la continuidad sistémica sino por aquellas que apuntan a prefigurar escenarios alternativos, aún en los marcos vigentes [...]. (THWAITES; OUVIÑA, 2016, p. 18)

Hay un acumulado de escenarios en la experiencia popular que se vivió inmediatamente antes y bajo los gobiernos progresistas. En primer lugar la importancia de la democracia participativa, la noción de que la sociedad civil es un proyecto autonómico de poder articulado a la lucha de las fuerzas políticas fuera y dentro de los gobiernos, hay objetivos centrales de la nueva lucha social que están incluidos en la noción antiproductivista y anticapitalista del buen vivir. Para construir una política de poder popular se hace necesaria 
una economía social y pública y una reforma intelectual, ética y de valores capaz de cuestionar el objetivo del lucro y la acumulación de capital. El Estado actual es heredero del colonialismo eurocéntrico y de la colonialidad del saber y el poder, etc.

\section{REFLEXIONES FINALES}

La política de hegemonía alternativa tiene como horizonte la lucha social y política por un nuevo bloque histórico que se base en la catarsis, esto es en proyectos de lucha social y política, e incluso de gobiernos, que expresen en su programa y sus políticas el espíritu de escisión y la autonomía integral de los nuevos explotados globales y del nuevo tejido social. Para ello es necesario pasar de la lucha por la recuperación del Estado a una política de hegemonía que parta de una noción integral y ética del Estado moderno como un poder en disputa, tanto en su contenido como en sus formas. La transformación no está en una política de Estado sino en la articulación del movimiento social con un proyecto alternativo de Estado y de sociedad civil.

\section{REFERÊNCIAS}

BETTO, Frei. "Começar de novo", Correio da cidadania (online),6 de septiembre de 2016. Disponible en: http://www.correiocidadania.com.br/colunistas/frei-betto. Consultado en 17 de ago. de 2017.

BETTO, Frei."Nos equivocamos”, Rebelión (online),03 de octubre de 2016. Disponible en: http://www.rebelion.org/noticia.php?id=217443. Consultado en 17 de ago. de 2017.

BRAGA, Ruy. Entrevista: Brasil: "Estamos recogiendo los frutos de 13 años de petismo en el gobierno federal", Correspondencia de prensa, world press, 22 de sept. de 2016.

FONTES, Virginia. Brasil e o Capital imperialismo. Rio de Janeiro, ed. UFRJ, 2010.

GAGO, Verónica. La razón neoliberal.Economías barrocas y pragmática popular. Chile, ed. Tinta Limón, 2014.

CASANOVA, Pablo.De la sociología del poder a la sociología de la explotación: pensar América Latina en el siglo XXI. Bogotá: Siglo del Hombre Editores y Clacso, 2009.

GRAMSCI, Antonio. Cuadernos de la Cárcel. México, Ed. ERA, 2000. 
HOUTART, Françoise. Entrevista de Laura Farina: ¿El final de un ciclo o el agotamiento del posneoliberalismo?Resumen Latinoamericano, 28 de sept. 2016.

MARINI, Ruy Mauro. Economía y democracia en América Latina.México, 1994. Documento de trabajo. Disponible en <marini-escritos.unam.mx> Consultado en 17 de ago. de 2017 :

MARX, Karl. Prólogo a la contribución a la crítica de la economía política.1859. Marxist internet Archive, 2001.

Apuntes preparatorios sobre la guerra civil en Francia. Varias ediciones. 1872.

OLIVER, Lucio. La ecuación Estado-sociedad civil en América Latina. México, ed. UNAM-La biblioteca, 2016.

OLIVER, Lucio. Transformaciones recientes de los Estados en América Latina. Una perspectiva a partir de la sociología política de Gramsci.México, Ed. FCPyS,UNAMBiblioteca, 2016.

SEMERARO, Giovanni. "Da libertação à hegemonia. Freire e Gramsci no processo de democratização do Brasil", Revista de Sociología y Política. Curitiba, v. 29, p. 95-104, noviembre de 2007.

TAPIA, Luis. La invención del núcleo común. Ciudadanía y gobierno multisocietal. La Paz, Bolivia, CIDES-UMSA, Postgrado en Ciencias del Desarrollo, 2006.

THWAITES, Mabel ; HERNÁN Ouviña. "Las disputas hegemónicas en América Latina del siglo XXI",CINAL, documento de trabajo presentado al Grupo de Estado en América Latina, CLACSO, Buenos Aires, 2016.

Recebido em 05/06/2017.

Aceito em 24/08/2017.

Publicado em 21/09/2017.

DOI: 10.11606/issn.1676-6288.prolam.2016.133387 